\title{
Failure of dams arranged in series or in complex
}

\author{
Benjamin Dewals • Sébastien Erpicum • Sylvain Detrembleur • \\ Pierre Archambeau • Michel Pirotton
}

Received: 26 March 2010/Accepted: 7 August 2010/Published online: 27 August 2010

(C) Springer Science+Business Media B.V. 2010

\begin{abstract}
A practical methodology has been developed for predicting flows generated by dam failures or malfunctions in a complex or a series of dams. A twofold approach is followed. First, the waves induced in the downstream reservoirs are computed, as well as hydrodynamic impacts induced on downstream dams and dikes are estimated. Second, the flood wave propagation and the inundation process are simulated in the downstream valley, accounting for possible dam collapse or breaching in cascade. Two complementary flow models are combined: a two-dimensional fully dynamic model and a simplified lumped model. At each stage, the methodology provides guidelines to select the most appropriate model for efficiently computing the induced flows. Both models handle parametric modeling of gradual dam breaching. The procedure also incorporates prediction of breach formation time and final width, as well as sensitivity analysis to compensate for the high uncertainties remaining in the estimation of breach parameters. The applicability of the modeling procedure is demonstrated for a case study involving a 70-m high-gravity concrete dam located upstream of four other dams.
\end{abstract}

Keywords Dam break in cascade - Dam breaching - Hazard analysis - Depth-averaged flow modeling $\cdot$ Finite volume $\cdot$ Breach parameters $\cdot$ Sensitivity analysis $\cdot$ Lumped model

B. Dewals $(\bowtie) \cdot$ S. Erpicum - S. Detrembleur · P. Archambeau · M. Pirotton Unit of Hydrology, Applied Hydrodynamics and Hydraulic Constructions,

Department ArGEnCo, University of Liege, Liège, Belgium

e-mail: B.Dewals@ulg.ac.be

URL: www.hach.ulg.ac.be

M. Pirotton

e-mail: hach@ulg.ac.be

URL: www.hach.ulg.ac.be

B. Dewals

Fund for Scientific Research, F.R.S.-FNRS, Brussels, Belgium 


\section{Introduction}

\subsection{Computation of dam break induced flows}

Dams and reservoirs are recognized for their valuable contribution to the prosperity and wealth of societies across the world, while they are also blamed for their risk of failure.

Failures of large dams have indeed caused catastrophic consequences, but past experience also reveals that loss of life and damage can be drastically reduced if Emergency Action Planning (EAP) is implemented. The development of EAP, such as risk analysis, should rely on a detailed prediction of the flood waves and inundation characteristics induced by dam failures.

Numerical modeling of such flows, involving the propagation of stiff fronts, requires a proper upwind numerical scheme to provide non-oscillatory stable solutions, while a satisfactory accuracy must be reached in space and time discretizations. Conservation of mass and momentum must be preserved during wetting and drying of computation cells as well as across discontinuities. For representing flows over irregular natural topographies, the model also needs a suitable discretization of the source term representing the bottom slope.

Many authors such as Fread (1984), Bellos and Sakkas (1987), Glaister (1988) or Alcrudo et al. (1992) have shown early interest in numerical computation of dam break waves and have developed various techniques to solve the 1D flow equations, as reported for instance by Garcia-Navarro et al. (1999).

Later, numerical solutions of the two-dimensional shallow-water equations for rapidly varying flows have lead to impressive results of practical interest, based on robust solvers usually achieving second-order accuracy in space and time. These models were based on finite difference schemes such as TVD Lax-Wendroff (Louaked and Hanich 1998) or TVD MacCormack schemes (Fennema and Chaudhry 1990; Tseng and Chu 2000), finite volume method, with fluxes mainly evaluated by Roe-type solvers (Alcrudo and Garcia-Navarro 1993; Anastasiou and Chan 1997; Brufau and Garcia-Navarro 2000), HLL Riemann solver (Caleffi et al. 2003; Garcia-Navarro et al. 1999; Mingham and Causon 1998) or other Flux Vector Splitting (Erpicum et al. 2010a), as well as on TVD discontinuous Galerkin finiteelement (e.g., Schwanenberg and Harms 2004).

Due to the large computational effort needed to solve the full Reynolds Averaged Navier-Stokes (RANS) equations, three-dimensional models remain hardly used for the practical simulation of dam break flood propagation on natural topography.

\subsection{Series or complexes of dams and reservoirs}

Such models are currently available for simulating the standard configuration of a flood wave resulting from the failure of a single dam. In contrast, other methodological issues arise when a series or a complex of dams is concerned since possible failures in cascade must be considered.

The probability that a downstream dam or dike fails as a result of being overtopped by the initial dam break wave depends on the damping that this wave undergoes during its propagation. Thus, for the case of dam series or complexes, the wave propagation in the downstream reservoirs needs to be predicted as accurately as possible. Prediction of failure of secondary structures, such as surrounding dikes, is also required since those failures may contribute to additionally damp the wave reaching other main dams downstream. 
Marche et al. (1997) simulated the response of a chain of reservoirs to an extreme input hydrograph. Comparisons were made between experimental data and predictions of three different flow models, namely a lumped model solving the continuity equation, a 1D finite difference model based on the Saint-Venant equations and a 2D finite volume model solving the shallow-water equations by means of a Roe-type Riemann solver. Differences in the models predictions were found consistent with the curvature of the free surface. The methodology was applied to reservoirs composed of a main dam and several surrounding dikes, referred to as "multidike" reservoirs.

\subsection{Present approach}

The present paper describes a procedure developed for efficiently conducting hazard analysis of a complex or a series of dams and reservoirs, based on accurate and efficient computation of induced flows and considering possible failures or breaching in cascade.

Apart from the dam body itself, failure of other system elements, such as penstocks, valves or gates, is also accounted for. Indeed, such events may have a higher probability of occurrence than the total collapse of a dam and may also be the cause for significant damages in the downstream valley.

The methodology combines two complementary flow models, namely a computationally very efficient lumped model and an advanced $2 \mathrm{D}$ one. A simple theoretical criterion of practical interest is provided to appreciate the validity of either model depending on the flow conditions, such as the stiffness of the inflow hydrograph and characteristics of the reservoir. Complementarities between the models are highlighted (Sect. 5.4). Onedimensional modeling may also be used for simulating wave propagation across long and narrow reservoirs (Marche et al. 1997; Kerger et al. 2009, 2010), whereas 3D modeling would not be practical due to the required computational time.

Dam breaching is incorporated in the $2 \mathrm{D}$ flow model based on a parametric timedependent topography representing the gradual development of the breach. In contrast to Marche et al. (1997), the flow is here computed both upstream and downstream as well as on the bottom of the breach, so that possible backwater effects are accounted for. In the lumped model, the breach opening is implemented as a time-dependent boundary condition. Breach geometry and formation time are estimated from standard prediction formulae, while the breach hydrograph is explicitly calculated by the flow models. To compensate for uncertainties remaining in the breach parameters, extensive sensitivity analysis is conducted based on the lumped model and, to a limited extent, on the 2D model.

An overview of the methodology is provided in the next section. The flow models and the simulation of dam breaching are respectively detailed in Sects. 3 and 4. The application of the methodology to a practical case study involving a complex of five dams is described in Sect. 5.

\section{Analysis of a complex or a series of dams}

As detailed in Fig. 1, the present methodology includes four steps, from the identification of relevant individual failure scenarios (step 1) to the computation of the hydraulic impacts in the downstream reservoirs (step 2), on dams and dikes located downstream, accounting for possible overtopping or failure in cascade (step 3), as well as in the downstream valley (step 4). 

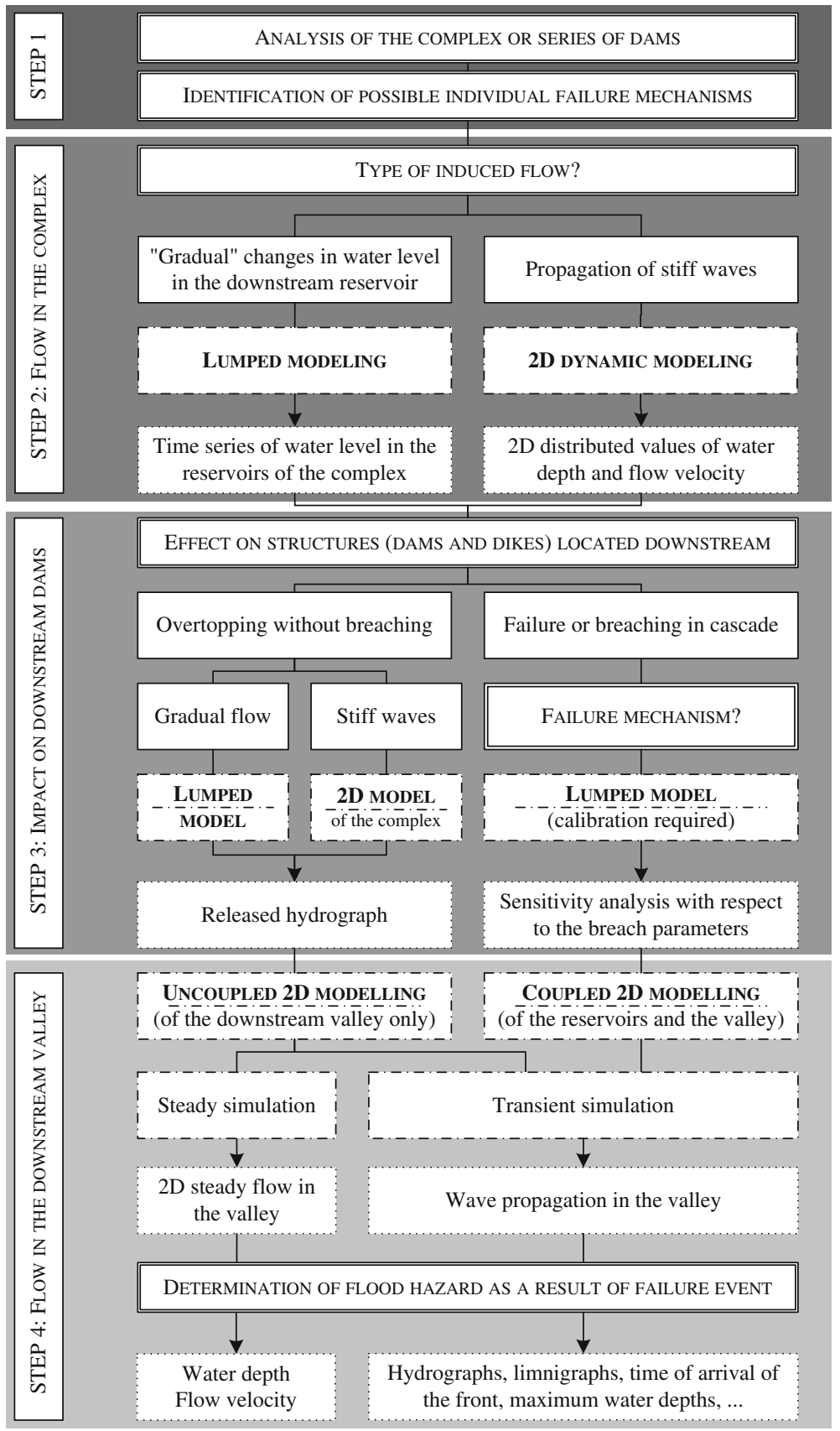

Fig. 1 Methodology for hazard analysis of complexes or series of dams 
Like in the approach detailed by Marche (2004), the hydrographs potentially released immediately downstream of the complex are computed for individual failure scenarios and the inundation in the downstream valley is subsequently simulated for selected representative scenarios.

\subsection{Step 1: Identification of individual failure scenarios}

Step 1 consists in identifying possible individual failure scenarios. Therefore, each dam or structure is reviewed and, by means of expert judgment and consultation with the dam operator, the possible malfunctions or failure mechanisms are defined in accordance with ICOLD's guidelines (ICOLD 1998).

\subsection{Step 2: Selection of a modeling approach}

Step 2 involves the computation of flows induced in the downstream reservoir. Therefore, the methodology combines a lumped model, solving the reservoir continuity equation, and a fully dynamic flow model providing accurate and conservative solutions of the 2D shallow-water equations. While the later is required for rapidly varying flow conditions in the reservoirs, involving the propagation of stiff fronts, the former turns out to be sufficient in cases where flow characteristics vary gradually in the reservoir, for which it leads to significant reductions in computation time. The $2 \mathrm{D}$ model is also exploited to compute the dam break wave propagation in the downstream valley.

A simple theoretical criterion for validity of the lumped model is presented in Sect. 3.3, providing a practical support for selecting the more appropriate modeling approach.

For long and narrow reservoirs, 1D modeling could also provide an appealing compromise between accuracy and computational effort (Marche et al. 1997), but it was not considered here due to intrinsic limitations to represent complex plane areas such as islands in the reservoirs or effects of strongly meandering channels.

\subsection{Step 3: Impact on downstream dams}

Based on the results of flow modeling in the reservoirs, step 3 consists in appreciating the hydrodynamic impact on structures (dams and dikes) located downstream and subsequently deducing their behavior as a result of being impacted by the initial dam break wave.

If the structures downstream are expected to sustain the overtopping flow and provided that the flow remains gradual in the reservoir, the lumped hydrodynamic model may be used to compute the hydrograph released downstream. For more extreme flow conditions, the lumped model is replaced by its $2 \mathrm{D}$ counterpart.

In contrast, if the downstream dam is expected to fail or to be breached as a result of the overtopping flow, the type of failure must be determined, and the corresponding breach parameters estimated.

Next, a sensitivity analysis of the peak breach discharge is conducted at this stage, involving repeated runs of the flow model.

For this purpose, the lumped model may be exploited to appreciate the sensitivity of the outflow hydrograph with respect to breach parameters, provided a proper calibration is performed since the theoretical conditions for validity of the lumped model are generally not strictly fulfilled for breach flows. 


\subsection{Step 4: Hydraulic impact in the valley}

If the crest of the downstream dam remains a critical section, the released hydrograph is obtained at the end of step 3. Therefore, the propagation of the flood wave in the downstream valley is computed based on a $2 \mathrm{D}$ simulation covering only the downstream valley.

In contrast, if the downstream dam fails or is breached, its crest does not remain a critical section and backwater effects thus need to be accounted for. In this case, the prediction of the flow released downstream of the complex is obtained as a result of a global 2D computation simulating the flows upstream in the reservoir, through the breach and in the downstream valley.

A post-processing of the $2 \mathrm{D}$ modeling results is eventually applied to generate hazard maps of practical interest for emergency planning and risk assessment.

\section{Flow modeling}

The flow models combined in the present methodology are described hereafter, while the conditions for validity of the lumped flow model are discussed in Sect. 3.3.

\subsection{D model}

The 2D model is based on the depth-averaged equations of mass and momentum conservation, namely the "shallow-water" equations. The large majority of flows occurring in rivers, even highly transient ones such as those induced by dam breaks, can reasonably be seen as shallow everywhere, except in the vicinity of singularities such as the wave tip.

The divergence form of the shallow-water equations includes the mass balance:

$$
\frac{\partial h}{\partial t}+\frac{\partial q_{j}}{\partial x_{j}}=0
$$

and the momentum balance:

$$
\frac{\partial q_{i}}{\partial t}+\frac{\partial}{j}\left(\frac{q_{i} q_{j}}{h}+g \frac{h^{2}}{2} \delta_{i j}\right)=g h\left(S_{0 i}-S_{\mathrm{f} i}\right)
$$

where Einstein's convention of summation over repeated subscripts has been used $(i=x$, $y$ ). In Eqs. 1 and 2, $t$ represents the time, $x$ and $y$ the space coordinates, $h$ the water depth, $q_{i}$ the unit discharge in direction $i, g$ the gravity acceleration, $\delta_{i j}$ the Kronecker symbol, $S_{0 i}$ the bottom slope and $S_{\mathrm{f} i}$ the friction slope, expressed by:

$$
S_{\mathrm{f} i}=\Delta \Sigma \tau_{\mathrm{b} i} / \rho=\sqrt{1+\left(\partial z_{\mathrm{b}} / \partial x\right)^{2}+\left(\partial z_{b} / \partial y\right)^{2}} \tau_{\mathrm{b} i} / \rho,
$$

where $\rho$ is the density of water, $z_{\mathrm{b}}$ the bottom elevation and $\tau_{\mathrm{b} i}$ the bottom shear stress, conventionally evaluated by an empirical law such as Manning formula. Consistently with Hervouet (2003), $\Delta \Sigma$ reproduces the increase in friction area as a result of an irregular topography.

The numerical model handles multiblock Cartesian grids. For the sake of computational efficiency, a grid adaptation procedure restricts the simulation domain to the wet cells. The space discretization is performed by a finite volume method achieving second-order accuracy in space and time. Flux evaluation is based on a stable flux vector splitting (FVS) 
developed by the authors, in which the upwinding direction of each term depends only on the sign of the flow velocity reconstructed at the cells interfaces (Erpicum et al. 2010a). This FVS enables a satisfactory adequacy with the discretization of the bottom slope term, which is a requirement for a horizontal water surface in a closed arbitrary basin to remain strictly horizontal at all times.

The time integration is performed by means of a second-order accurate explicit RungeKutta algorithm. For stability reasons, the time step is constrained by the CourantFriedrichs-Levy condition. A semi-implicit treatment of the bottom friction term is used (Caleffi et al. 2003), without requiring additional computational cost.

Besides, wetting and drying of cells is handled free of mass and momentum conservation error by means of an iterative resolution of the continuity equation (Erpicum 2006). A three-step procedure is followed at each time step: continuity equation is first evaluated; second, algorithm detects cells with a negative flow depth to reduce the outflow unit discharge such that the computed water depth in these cells becomes strictly equal to zero; finally, since these flux corrections may induce the drying in cascade of neighboring cells, the first two steps are repeated iteratively. Momentum equations are finally computed based on the corrected unit discharge values. In most practical applications, no more than two iterations are necessary.

The numerical model has already proved its validity and efficiency for a wide range of applications that were documented in previous papers. Validation was conducted by comparisons with analytical solutions of moving hydraulic jump or idealized dam break flows (Erpicum et al. 2010a), with field data (Dewals et al. 2008a; Erpicum et al. 2010b, Khuat Duy et al. 2010), as well as with experimental data in various configurations such as steady flow in rectangular reservoirs (Dewals et al. 2008b) or in macro-rough channels (Erpicum et al. 2009), dike break flow (Roger et al. 2009) and flow influenced by bottom curvature (Dewals et al. 2006a). Among others, benchmarks from EU Projects such as CADAM and IMPACT were tested successfully, including dam break flows in an L-shaped channel, in a rough channel with a bump (Erpicum et al. 2010a) or nearby an isolated building (Dewals 2006). In addition, maximum water depth and propagation time were properly predicted for the Malpasset dam break (Dewals et al. 2006b), confirming that the model is able to represent highly unsteady flows involving flow regime changes and propagation of stiff waves.

\subsection{Lumped model}

The lumped model exploited for describing gradually varying flows in the reservoirs is based on the reservoir continuity equation, obtained by integrating (Eq. 1) on the whole reservoir surface:

$$
\frac{\partial}{\partial t} \int_{A_{k}} h \mathrm{~d} A+\int_{\Gamma_{k}} \vec{q} \cdot \mathrm{d} \vec{\Gamma}=0 \Leftrightarrow \frac{\mathrm{d} V_{k}}{\mathrm{~d} t}=A_{k} \frac{\mathrm{d} z_{s, k}}{\mathrm{~d} t}=Q_{\mathrm{in}, k}-Q_{\text {out }, k}, \quad k=1, \ldots, N_{R}
$$

where $A_{k}$ and $\Gamma_{k}$ represent respectively the surface and contour of reservoir $k, V_{k}$ the volume of water stored in the reservoir, $q$ the unit discharge normal to the reservoir contour, while $Q_{\mathrm{in}, k}$ and $Q_{\mathrm{out}, k}$ designate respectively the total inflow and outflow discharges. $N_{R}$ is the number of reservoirs. As shown in Eq. 4, the reservoir continuity equation can alternatively be expressed as a function of the water level $z_{\mathrm{s}, k}$, using the stagestorage relationship of the reservoir. 
$Q_{\mathrm{in}, k}$ is typically given by a hydrograph corresponding to a flood wave reaching the reservoir, possibly due to the failure of an upstream dam, whereas $Q_{\text {out }}$ represents the sum of all releases through spillways and outlets plus outflows due to crest overtopping and breach outflows.

The set of equations (Eq. 4) constitutes a system of $N_{\mathrm{R}}$ ordinary differential equations, which are solved using an explicit time integration scheme. Initial storage in each reservoir must be prescribed.

\subsection{Validity of the lumped model}

The main simplifying assumption required to derive the lumped model from the twodimensional model consists in disregarding equations (Eq. 2) and considering the water surface elevation as horizontal. For the purpose of appreciating the validity of this assumption, the orders of magnitude of the different terms in Eq. 2 were compared based on a non-dimensional form of the equations.

Therefore, the following notations were introduced: $H=$ characteristic water depth; $L=$ characteristic horizontal length scale; $\Delta Z=$ characteristic variation of the free surface elevation $z_{\mathrm{s}}=z_{\mathrm{b}}+h ; Q_{\text {in }}=$ characteristic inflow discharge; $T_{\text {in }}=$ characteristic time; $\Omega=$ characteristic cross-section of the reservoir and $J=$ characteristic friction slope.

Non-dimensional variables (noted with a prime) were defined as follows:

$$
\begin{aligned}
& h=H h^{\prime} ; \quad x=L x^{\prime} ; \quad t=T_{\text {in }} t^{\prime} ; \\
& \frac{\partial z_{s}}{\partial x_{i}}=\frac{\Delta Z}{L} \frac{\partial z_{s}^{\prime}}{\partial x_{i}^{\prime}} ; \quad q_{i}=H \frac{Q_{\text {in }}}{\Omega} q_{i}^{\prime} ; \quad S_{\mathrm{f} i}=J S_{\mathrm{f} i}^{\prime} .
\end{aligned}
$$

Hence, Eq. 2 could be rewritten in the following non-dimensional form, involving a Strouhal number St and a Froude number $\mathrm{Fr}_{*}$ :

$$
\begin{aligned}
& \mathrm{St} \frac{\partial q_{i}^{\prime}}{\partial t^{\prime}}+\frac{\partial}{\partial x_{j}^{\prime}}\left(\frac{q_{i}^{\prime} q_{j}^{\prime}}{h^{\prime}}\right)+\frac{1}{\mathrm{Fr}_{*}^{2}} \frac{\Delta Z}{H} h^{\prime} \frac{\partial z_{s}^{\prime}}{\partial x_{i}^{\prime}}=-\frac{1}{\operatorname{Fr}_{*}^{2}} \frac{J L}{H} h^{\prime} S_{\mathrm{f} i}^{\prime} ; \quad i=x, y \\
& \text { with } \mathrm{St}=\frac{\Omega L}{T_{\text {in }} Q_{\text {in }}}=\frac{V}{T_{\text {in }} Q_{\text {in }}}, \quad \operatorname{Fr}_{*}=\frac{Q_{\text {in }} / \Omega}{\sqrt{g H}}=\frac{T_{\text {in }} Q_{\text {in }}}{V} \frac{L / \sqrt{g H}}{T_{\text {in }}}
\end{aligned}
$$

and the reservoir storage $V=\Omega$ L.Using the assumption of shallow flow $(H<L)$, the order of magnitude of $\Delta \mathrm{Z} / L$ is bounded by:

$$
\frac{\Delta Z}{L} \leq \frac{\Delta Z}{H} \leq \max \left(\mathrm{St} \mathrm{Fr}_{*}^{2}, \mathrm{Fr}_{*}^{2}, \frac{J L}{H}\right)
$$

Since the analysis focuses on the influence of inflows in the reservoir, the friction slope $J$ may be assumed not to have a dominating role (i.e., $J L \ll H$ ); therefore, the conditions for the free surface elevation to remain almost horizontal are:

$$
\mathrm{St} \mathrm{Fr}_{*}^{2}=\frac{T_{\text {in }} Q_{\text {in }}}{V}\left(\frac{L / \sqrt{g H}}{T_{\text {in }}}\right)^{2} \ll 1, \quad \text { and } \quad \operatorname{Fr}_{*}^{2}=\left(\frac{T_{\text {in }} Q_{\text {in }}}{V}\right)^{2}\left(\frac{L / \sqrt{g H}}{T_{\text {in }}}\right)^{2} \ll 1 .
$$

Equation 8 expresses that the inflow volume must be limited compared to the reservoir storage and that the wave propagation time in the reservoir must remain low enough compared to the characteristic time of the inflow hydrograph. 
Both inequalities in Eq. 8 constitute a practical quantitative criterion for assessing the validity of the lumped model.

\section{Modeling breaching of embankment dams}

\subsection{Existing modeling approaches}

Mechanisms of breaching of embankment dams show a high variability and are still poorly understood. Therefore, a high level of uncertainty remains in current predictions of breach parameters.

Two main approaches may be distinguished for evaluating breach characteristics and induced flows: either process-oriented modeling or empirical prediction formulae as well as guidelines.

Process-oriented modeling may involve semi-analytical approaches as well as 1D, 2D or 3D numerical simulations, possibly accounting for slope instabilities and bank collapses. Their predictive capacity is however reduced for practical applications usually involving complex non-homogeneous dams, graded material or cohesive sediments.

Guidelines usually provide conservative upper bounds of breach parameters. They are thus not suitable to obtain best estimates of breach geometry and outflow in the framework of a risk analysis, but they may be applied if the aim of the analysis is focused on planning emergency response.

Prediction formulae consist in statistical regressions obtained from database of reported dam breaching accidents. Although uncertainties affecting the predictions remain high, such formulae offer the advantage of being simple to use for practical applications. Indeed, required inputs are particularly easy to obtain, such as storage in the reservoir at the time of failure and initial water depth in the reservoir measured above the final breach elevation.

Therefore, given the lacks in the present understanding of actual failure mechanisms and the scarcity of available data in many cases of practical interest, such formulae were regarded here as a reasonable approach for their simplicity guarantying wide applicability.

The obtained breach parameters were subsequently exploited in parametric representations of the breach development, coupled with the flow models, as detailed in the next paragraphs. The breach outflow is thus explicitly computed by the flow models, enabling to represent the hydraulic coupling between reservoir depletion, flow through the breach and possible backwater effects downstream.

\subsection{Time-varying topography in the $2 \mathrm{D}$ flow model}

The parametric breach model was implemented in the 2D flow model by means of a timevarying topography. This procedure requires the definition of (i) a control area and criterion for breach initiation; (ii) the final breach geometry and (iii) the failure mode as well as formation time.

The control area for breach initiation is a user-defined subset of computation cells in which a criterion for breach initiation is checked at each time step. The control area typically covers the cells of the embankment crest.

Since forecasting breach initiation remains extremely difficult due to the high variability in the governing phenomena and parameters, predictive models are hardly available. Therefore, the present methodology incorporates several types of criteria of breach initiation, formulated as a threshold value of discharge, water depth or mean velocity of the 
overtopping flow. Once the computational model detects that this threshold is exceeded, it triggers the time evolution of the topography.

A sensitivity analysis of breach outflow with respect to failure criterion was undertaken and revealed a limited influence for overtopping of rockfill dams, as also reported by other authors such as Singh and Snorrason (1984).

As sketched in Fig. 2, the final breach geometry is defined by the user based on the digital surface model (DSM) used for flow modeling. The mean breach width and side slopes are set in accordance with the breach parameters deduced from the prediction formulae. The breach shown in Fig. 2 is trapezoidal for simplicity of representation, whereas the actual breach in the defined DSM may have any arbitrarily complex shape.

Next, the user selects one of the different implemented failure modes, such as a simple decrease in the crest elevation, the breach bottom remaining horizontal or more realistic mechanisms involving for instance a gradual reduction in the slope of the downstream face of the dam, as shown in Fig. 3. They are respectively referred to as failure mode nos. 1 and 2. The later failure mode is consistent with experimental observations of breaching of embankments made of non-cohesive material such as rockfill (e.g., Dupont et al. 2007). The total breach formation time is prescribed based on a prediction formula, and the breach opening is assumed to progress linearly with time.

(a)

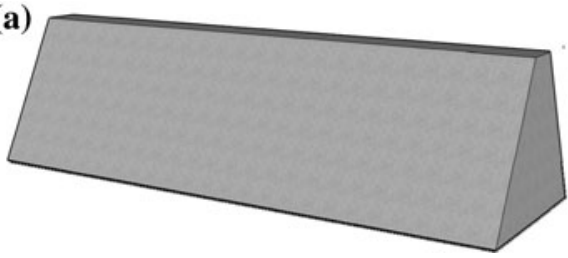

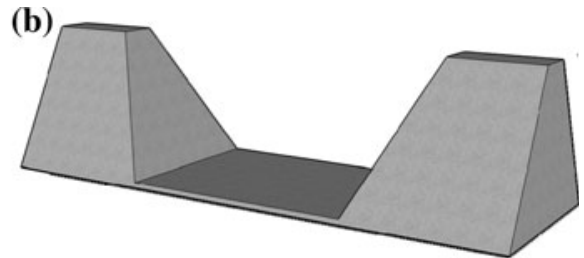

Fig. 2 Definition of the time-dependent topography implemented within the 2D flow model. Example of initial embankment dam (a) and user-defined final breach topography (b)

(a)

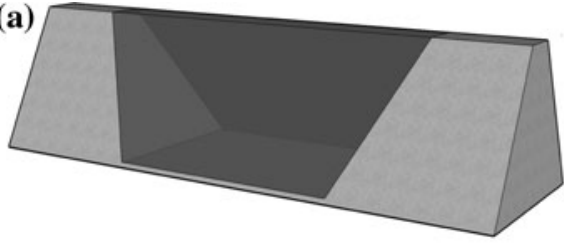

(c)

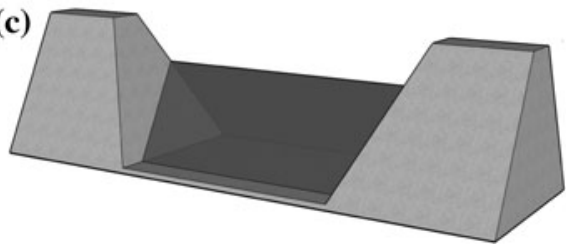

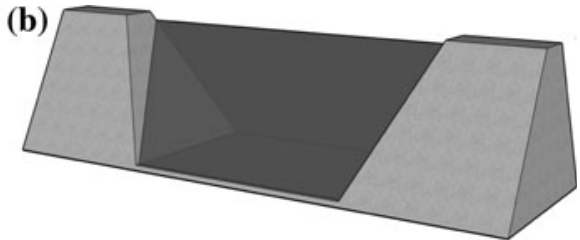

(d)

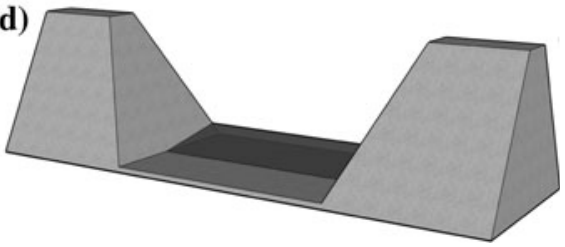

Fig. 3 Sequence of time-varying topography as implemented within the 2D flow model, showing breach development according to failure mode no. 2 
4.3 Implementation of the procedure in the lumped model

Parametric breach modeling was also implemented in the lumped flow model for the purpose of efficiently conducting sensitivity analyses. The breach outflow was evaluated by a weir-type formula:

$$
Q_{\mathrm{B}}=b \mu \sqrt{2 g\left[\max \left(z_{\mathrm{s}}-z_{\mathrm{B}}, 0\right)\right]^{3}},
$$

where $Q_{\mathrm{B}}$ is the breach outflow, $b$ the breach width, $\mu$ the discharge coefficient, $z_{\mathrm{s}}$ the free surface elevation in the reservoir and $z_{\mathrm{B}}$ the breach bottom elevation. Parameters $z_{\mathrm{B}}$ and $b$ are time dependent to account for breach development and for possible non-rectangular breach geometry.

Unfortunately, coefficient $\mu$ is not a known constant for dam breach flows. Its variation must be calibrated on a case-by-case basis or may be calculated from empirical formulations such as, for instance, those developed by Kamrath et al. (2006). Backwater effects are hence indirectly accounted for through the variation of $\mu$, but they are not explicitly computed by the flow model.

\subsection{Breach parameters}

Breach parameters are obtained from the main characteristics of the reservoir using the prediction formulae developed by MacDonald and Langridge-Monopolis (1984), Von Thun and Gillette (1990) and Froehlich (1987, 1995).

The formulae of MacDonald and Langridge-Monopolis are based on 42 historical cases. They achieve a better correlation for the volume of eroded material than they do for the breach formation time, which tends to be overestimated. Von Thun and Gillette used an extended set of data to develop prediction formulae for average breach width and formation time (Wahl 1998). Finally, based on 63 historical cases, Froehlich provides estimates of the breach width and formation time.

\subsection{Sensitivity analysis}

The breach parameters obtained from the above-mentioned prediction formulae remain affected by significant uncertainties, as confirmed by Wahl (2004). Therefore, a two-step approach has been followed, involving first the evaluation of "best estimates" of breach parameters based on the prediction formulae and next a sensitivity analysis of the results with respect to the breach parameters.

Sensitivity analyses of the breach outflow were undertaken based on both the lumped and the 2D models, whereas the later also enables sensitivity analysis of the inundation characteristics in the downstream valley.

Although quantitative results vary on a case-by-case basis, such sensitivity analyses basically reveal that for large impounded storage (resp. narrow breach), breach outflow is significantly influenced by the breach width, whereas it remains essentially insensitive to the breach formation time (Dewals et al. 2007; Singh and Snorrason 1984). In contrast, for smaller reservoirs (resp. wider breach), the formation time has more influence on the outflow discharge than the breach width. For practical applications, such results contribute to a straightforward identification of the more influential breach parameters and consequently to prioritize resources toward a more careful estimation of their value. 


\section{Case study}

\subsection{Complex of dams}

A complex of five dams and two main reservoirs was used as a case study to demonstrate the applicability of the methodology. Figure 4 shows the global configuration of the complex, the aims of which are regulation of low-flows in downstream waterways and pumped storage hydroelectricity production.

The main dam (no. 1), a 50-m high concrete gravity dam, is located upstream of four other dams, including a 20-m high rockfill embankment (dam no. 2, located most downstream). Failure of dam no. 1 is hence likely to induce other failures in cascade.

Dams of the complex have small catchments, namely $8 \mathrm{~km}^{2}$ for dam no. 1 and $80 \mathrm{~km}^{2}$ for dam no. 2, while the storage capacity is respectively $68 \times 10^{6}$ and $15 \times 10^{6} \mathrm{~m}^{3}$ in the upper and the lower reservoirs.

For the sake of tourism and water sports, dams no. 3-5 are used to keep a constant level on their upstream side in spite of level variations in the lower reservoir due to pumped storage hydroelectricity production.

\subsection{Available data}

Accurate topography data are available for inundation modeling in the downstream valley. They were collected by regional water authorities using airborne laser altimetry (LIDAR)

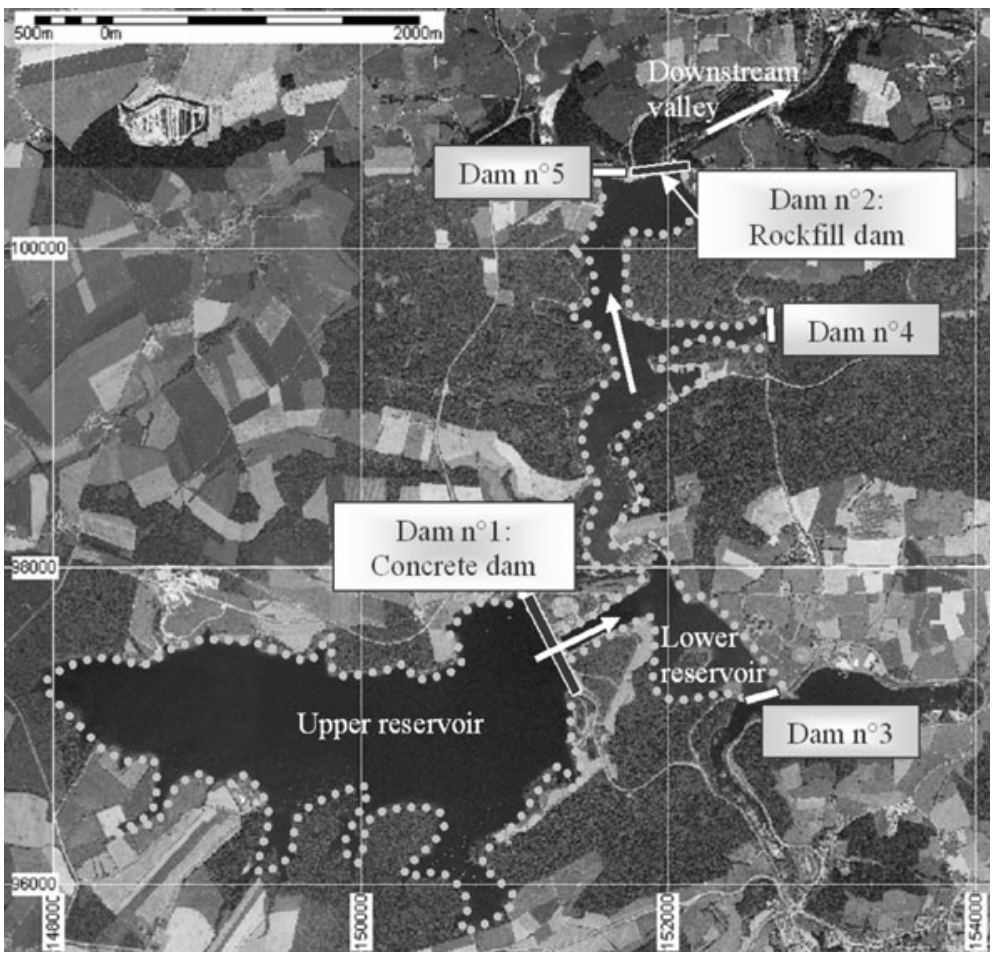

Fig. 4 Layout of the complex of five dams considered in the case study 
and constitute a digital surface model (DSM) of the floodplains characterized by a horizontal resolution of $1 \mathrm{~m}$ by $1 \mathrm{~m}$ and a vertical accuracy of $15 \mathrm{~cm}$. As regards the main riverbed, cross-sections available every $50 \mathrm{~m}$ were interpolated to generate a twodimensional bathymetry that was incorporated into the DSM. Based on digitalized maps and plans of the structures, the bathymetry of the reservoirs and the dams were accurately included into the DSM as well.

Although flow simulations were eventually conducted on grids of $8 \mathrm{~m}$ by $8 \mathrm{~m}$, the topography matrix used for flow modeling still satisfactorily represented the macroroughness effect of the main buildings, and thus no artificial increase in the roughness coefficient was needed in urbanized areas (Dewals 2006).

In contrast, since a significant part of the area nearby the complex is covered with forests, the friction coefficient was spatially distributed to reproduce the increased flow resistance in such densely vegetated areas. The friction coefficient was distributed as a function of the vegetation height, deduced from the local difference between the first and last echoes of the laser altimetry, corresponding respectively to the top of vegetation and to the ground level. The Manning coefficient $n$ is varied between 0.03 and $0.15 \mathrm{~s} / \mathrm{m}^{1 / 3}$, consistently with findings of the EC research project RESCDAM, during which experiments were carried out in flumes with highly transient flows in the presence of various vegetation types (RESCDAM 2000).

\subsection{Application of the methodology}

Individual failure scenarios for each dam were first defined based on the experience of the dam operator and on a comprehensive analysis of the complex, the detailed analysis of which lies beyond the scope of the present paper (Dewals 2006). As far as the main upstream dam (no. 1) is concerned, two critical failure scenarios were identified, namely the failure of penstocks supplying the power station situated at the toe of the dam and the collapse of the dam itself. The former scenario may result from material or weld defect, or from sabotage, whereas the later may typically be caused by earthquake.

In accordance with ICOLD's guidelines for concrete dams, the collapse of dam no. 1 was considered as total and instantaneous (ICOLD 1998). Using the 2D unsteady flow model, it was verified that the corresponding peak outflow is only $15 \%$ higher than the peak discharge resulting from a $200-\mathrm{m}$ breach located in the middle of the $800-\mathrm{m}-$ long dam crest. Higher water depths in the center of the valley, where the narrower breach is located, explain this low sensitivity of the peak outflow.

For each scenario, Table 1 provides an overview of the main steps of the analysis, stating the flow model used, the time dependency represented and the level of coupling between flows in the reservoirs and in the downstream valley.

Table 1 Summary of the application of the analysis procedure for the case study

\begin{tabular}{llll}
\hline $\begin{array}{l}\text { Step 1: Individual failure } \\
\text { scenarios }\end{array}$ & $\begin{array}{c}\text { Scenario 1: Failure } \\
\text { of penstocks at dam no. 1 }\end{array}$ & $\begin{array}{c}\text { Scenario 2: Total } \\
\text { collapse of dam no. 1 }\end{array}$ \\
$\begin{array}{c}\text { Step 2: Flow in the } \\
\text { reservoirs }\end{array}$ & $\begin{array}{l}\text { Flow model } \\
\text { Time dependency }\end{array}$ & $\begin{array}{l}\text { Lumped } \\
\text { Unsteady } \\
\text { Overtopping without }\end{array}$ & 2D \\
$\begin{array}{c}\text { Step 3: Impact on } \\
\text { downstream dam }\end{array}$ & & $\begin{array}{c}\text { Unsteady } \\
\text { breaching }\end{array}$ & $\begin{array}{c}\text { Overtopping triggering } \\
\text { failures in cascade }\end{array}$ \\
$\begin{array}{c}\text { Step 4: Inundation in the } \\
\text { downstream valley }\end{array}$ & $\begin{array}{l}\text { Flow model } \\
\text { Coupling }\end{array}$ & $\begin{array}{l}\text { 2D } \\
\text { Tncoupled }\end{array}$ & 2D \\
& Time dependency & Steady & Coupled \\
& & Unsteady \\
\hline
\end{tabular}


As detailed in the following paragraphs, the flow induced in the downstream reservoir by scenario 1 remains gradual, and dam no. 2 is expected not to be breached in spite of a moderate overtopping. The lumped model applies to compute the outflow hydrograph downstream of the complex, without calibration since the crest of dam no. 2 remains a critical section. A detailed sensitivity analysis was carried out very efficiently using the lumped model, whereas the 2D flow model was used for inundation modeling in the downstream valley by means of a steady simulation.

In contrast, for scenario 2 , dam no. 2 would be severely overtopped and consequently breached, so that no control section remains, and only the $2 \mathrm{D}$ model is strictly valid. Anyway, the lumped model remains a valuable tool to appreciate the sensitivity of the breach discharge with respect to breach parameters, provided a calibration is performed based on the results of the 2D model that reproduces backwater effects.

The following paragraphs detail the analysis of these failure scenarios in accordance with the methodology depicted in Fig. 1.

\subsection{Scenario 1: Failure of penstocks}

As a result of the failure of penstocks at dam no. 1, water released from the upper reservoir flows into the lower one and possibly overtops dam no. 2.

This process was computed using the lumped model, simulating both the drawdown of the upper reservoir and the flow in the lower reservoir based on two coupled equations similar to Eq. 4:

$$
\frac{\mathrm{d} V_{1}}{\mathrm{~d} t}=-Q_{1, \text { out }} \quad \text { and } \quad \frac{\mathrm{d} V_{2}}{\mathrm{~d} t}=Q_{1, \text { out }}-Q_{2, \text { out }} .
$$

The inflow into the lower reservoir simply corresponds to the discharge $Q_{1, \text { out }}$ released from the upper one, while the discharge $Q_{2, \text { out }}$ released from the lower reservoir encompasses the water released through the spillway and by overtopping of dam no. 2 :

$$
\begin{gathered}
Q_{1, \text { out }}=N A \sqrt{\alpha 2 g\left(Z_{1}-Z_{2}\right)}, \\
Q_{2, \text { out }}=b_{2}^{\text {Spil. }} \mu_{2}^{\text {Spil. }} \sqrt{2 g\left[\max \left(Z_{2}-Z_{2}^{\text {Spil. }}, 0\right)\right]^{3}}+b_{2}^{\text {Crest }} \mu_{2}^{\text {Crest }} \sqrt{2 g\left[\max \left(Z_{2}-Z_{2}^{\text {Crest }}, 0\right)\right]^{3}}
\end{gathered}
$$

where $N$ designates the number of failed penstocks $(N=1,2,3$ or 4$), A\left(\mathrm{~m}^{2}\right)$ is the crosssection of one penstock (diameter: $D=4.5 \mathrm{~m}$ ), $Z_{1}$ and $Z_{2}$ represent respectively the water levels in the upper and lower reservoirs, and $\alpha=\left(1+k_{1}+k_{2}\right)^{-1}$ encompasses the local head loss coefficients at the entry $\left(k_{1}=0.5\right)$ and outlet $\left(k_{2}=1\right)$ of the penstocks. Due to the short length, continuous head losses were neglected. $b_{2}^{\text {Spil. }}, \mu_{2}^{\text {Spil. }}$ and $Z_{2}^{\text {Spil. }}$ represent respectively the width, the discharge coefficient and the level of the spillway of dam no. 2; while $b_{2}^{\text {Crest }}, \mu_{2}^{\text {Crest }}$ and $Z_{2}^{\text {Crest }}$ refer to the same characteristics for the whole crest of dam no. 2 .

As shown in Table 2, the non-dimensional numbers (Eq. 8) were evaluated to check the validity of the lumped model in the present case. Based on Eq. 11 evaluated at the initial time and considering the simultaneous failure of all penstocks $(N=4)$, the characteristic discharge $Q_{\text {in }}$ was set to $1,300 \mathrm{~m}^{3} / \mathrm{s}$, whereas $T_{\text {in }}$ was estimated as half the time required for complete emptying of the upper reservoir assuming constant outflow discharge. The characteristic length and depth of the lower reservoir are respectively $L=3,500 \mathrm{~m}$ and $H=18 \mathrm{~m}$, while its storage was used to set $V=15 \mathrm{M} \mathrm{m}^{3}$. Results shown in Table 2 
Table 2 Value of the nondimensional numbers (Eq. 8) for scenario 1 and scenario 2

\begin{tabular}{lll}
\hline & Scenario 1 & Scenario 2 \\
\hline$Q_{\text {in }}\left(\mathrm{m}^{3} / \mathrm{s}\right)$ & 1,300 & $3 \times 10^{4}$ \\
$T_{\text {in }}\left(\mathrm{m}^{3}\right)$ & $2.6 \times 10^{4}$ & 300 \\
$V\left(\mathrm{~m}^{3}\right)$ & $15 \times 10^{6}$ & $15 \times 10^{6}$ \\
$L(\mathrm{~m})$ & 3,500 & 3,500 \\
$H(\mathrm{~m})$ & 18 & 18 \\
$T_{\text {in }} Q_{\text {in }} / V$ & 2.3 & 0.6 \\
$L(g H)^{-1 / 2} / T_{\text {in }}$ & 0.01 & 0.9 \\
$\mathrm{Fr}_{*}^{2}$ & $5 \times 10^{-4}$ & $3 \times 10^{-1}$ \\
$\mathrm{St} \mathrm{Fr}_{*}^{2}$ & $2 \times 10^{-4}$ & $5 \times 10^{-1}$ \\
\hline
\end{tabular}

confirm the validity of the lumped model since both non-dimensional numbers are in the range $2 \times 10^{-4}-5 \times 10^{-4}$.

In addition, Fig. 5 corroborates the adequacy between results of the lumped and the 2D model for predicting the outflow hydrograph released downstream of dam no. 2. For a better comparison, the same inflow hydrograph $Q_{1 \text {,out }}$ entering the lower reservoir was prescribed in both models. This hydrograph was computed separately by the lumped model solving only (Eq. 10) and temporarily neglecting head losses $(\alpha=1)$. Due to the high computation time required by the $2 \mathrm{D}$ model, it was run for a duration just sufficient to demonstrate the agreement between the results of both models. The difference in peak discharge is found to remain lower than $1 \%$ (Fig. 5).

Next, the lumped model was used to compute flows induced by the failure of the penstocks and to conduct sensitivity analysis at very low CPU cost. At this stage, the coupling between the evolution of both reservoirs was considered by solving simultaneously both equations (Eq. 10). The influence of the initial level in the lower reservoir was first investigated. Assuming a low initial level $(202.5 \mathrm{~m})$ instead of the highest operation level $(208.4 \mathrm{~m})$, leads to a decrease in the maximum free surface elevation of no

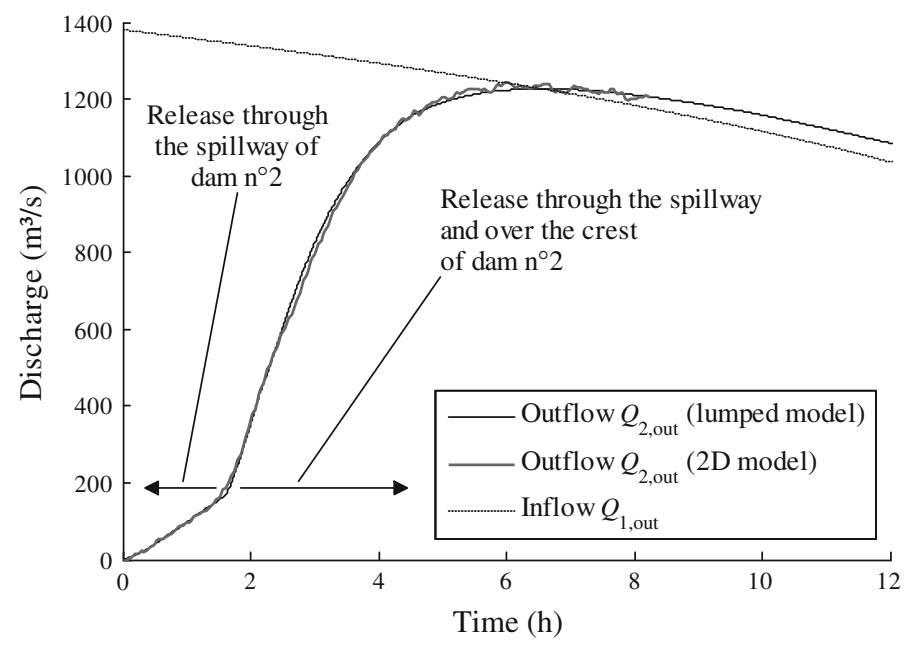

Fig. 5 Hydrographs representing the inflow into the lower reservoir $\left(Q_{1 \text {,out }}\right)$ and the discharge $Q_{2, \text { out }}$ released downstream of dam no. 2, computed with the lumped model and the $2 \mathrm{D}$ model 
more than $5 \mathrm{~cm}$, due to the long duration of the inflow hydrograph. The reduction in the peak outflow is thus limited to $5 \%$. However, thanks to the higher freeboard, significant delays were found in the time of crest overtopping ( $1 \mathrm{~h}$ and $50 \mathrm{~min}$ ) and time of maximum outflow (1 $\mathrm{h}$ and $40 \mathrm{~min}$ ), facilitating thus emergency response and evacuation planning in the downstream valley.

The lumped model was subsequently exploited to test opportunities of emergency response such as preventive operation of gates at spillway of dam no. 2, enabling to release earlier a higher controlled discharge and consequently reduce the peak outflow. Opening these gates was found to completely prevent dam no. 2 from overtopping if not all penstocks fail simultaneously. The model also enabled to optimize the time at which gates of dam no. 2 should be opened to prevent overtopping without unnecessarily reducing time available for evacuation.

Flows induced in the lower reservoir were found to remain gradual and characterized by low rising rates unlikely to produce dynamic loads on surrounding dams, which are thus unlikely to fail in cascade. In addition, it was shown that proper emergency response may prevent overtopping of dam no. 2. Since the crest of this dam remains a critical section, flow computation in the downstream valley was performed based on a simulation domain covering the valley but not the reservoirs. Released hydrographs could have been prescribed as an upstream boundary condition, but due to their long duration compared to the wave propagation time in the downstream valley, inundation modeling was carried out by means of a steady flow computation, corresponding to the peak outflow. Provided arrival time of the wave is not sought, such steady approach turns out to be sufficient and efficient.

\subsection{Scenario 2: Total collapse of the upstream dam}

\subsubsection{Flow in the reservoirs and impact on downstream dams}

The $2 \mathrm{D}$ flow model was exploited to simulate the propagation of the waves induced in the lower reservoir by the total collapse of dam no. 1. As a result, the characteristics of the overtopping waves reaching each downstream dam were obtained and revealed significant impacts on the structures (Fig. 6).

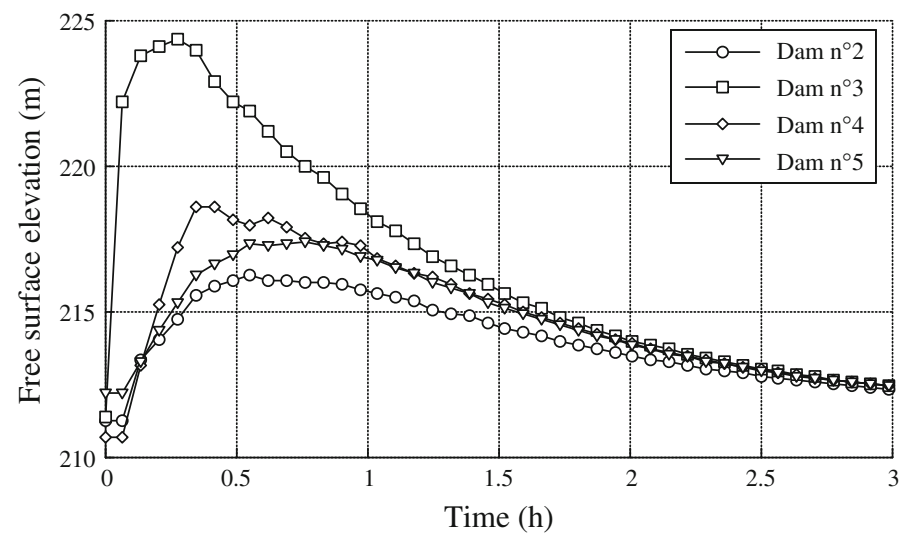

Fig. 6 Free surface elevations in the reservoirs near the four downstream dams, after the instantaneous and total collapse of dam no. 1 
Indeed, the downstream rockfill dam (no. 2) was found to be overtopped by a 5-m-high wave, corresponding to a maximum discharge of about $Q \approx 10,000 \mathrm{~m}^{3} / \mathrm{s}$ and a unit discharge exceeding $q \approx 40 \mathrm{~m}^{2} / \mathrm{s}$. Similarly, the overtopping waves over the three other dams were respectively evaluated at $15 \mathrm{~m}$ (dam no. 3 ), $8 \mathrm{~m}$ (dam no. 4 ) and $5 \mathrm{~m}$ (dam no. $5)$, with maximum discharges of $35,000 \mathrm{~m}^{3} / \mathrm{s}\left(q \approx 155 \mathrm{~m}^{2} / \mathrm{s}\right), 5,480 \mathrm{~m}^{3} / \mathrm{s}\left(q \approx 22 \mathrm{~m}^{2} / \mathrm{s}\right)$ and $720 \mathrm{~m}^{3} / \mathrm{s}\left(q \approx 4 \mathrm{~m}^{2} / \mathrm{s}\right)$.

Consequently, concrete dams no. 3 and 4 were assumed to fail in cascade, as confirmed by assessing the resultant forces and moments they undergo during their overtopping compared to normal operation conditions (Dewals 2006).

Their collapse was reproduced in the final simulation (step 4) by means of a time-varying embankment topography triggered once the flow model detects their overtopping (Dewals et al. 2006b). On the contrary, embankment dam no. 5 was supposed not to be breached considering that the unit discharge remains of the order of $4 \mathrm{~m}^{2} / \mathrm{s}$ and the hydrodynamic loads are hence significantly weaker than for dams no. 3 and 4.

As regards the downstream rockfill dam (no. 2), it is also expected to be breached by the overtopping flow, and corresponding breach parameters were estimated. Since dam no. 2 is built from "random" rockfill, including boulders as large as $1 \mathrm{~m}^{3}$, embankment material may not be considered as a continuous medium compared to expected water depths. Therefore, as discussed in Sect. 4, process-oriented modeling would hardly apply, whereas the present procedure based on prediction formulae and parametric modeling turns out to be more appropriate.

Both formulae developed by Froelich were used, as well as those from Von Thun and Gillette. Since the dataset used by MacDonald and Langridge-Monopolis is older and was incorporated in data used for developing the Von Thun and Gillette formulae, those of MacDonald and Langridge-Monopolis were not used here.

Input data for all formulae include the storage or released volume of water $\left(V=85 \times 10^{6} \mathrm{~m}^{3}\right)$. The storage of both reservoirs was considered in the prediction formulae since it corresponds indeed to the total volume of water eventually released through the breach and thus contributing to the erosion process. Froehlich formulae also require the breach height $\left(h_{\mathrm{b}}=23.5 \mathrm{~m}\right)$, whereas Von Thun and Gillette formulae rely on the water depth at the dam before breach formation, measured above the final breach bottom $\left(h_{\mathrm{w}}=28.5 \mathrm{~m}\right.$, considering a 5-m-high overtopping wave as shown in Fig. 6). Von Thun and Gillette proposed two methods for estimating breach formation time, either based on water depth $h_{\mathrm{w}}$ or using the lateral erosion rate $B / h_{\mathrm{w}}$, deduced from the predicted breach width $B$ (Wahl 1998). For both methods, prediction equations are provided for "erosion resistant" materials and for "easily erodible" ones, corresponding to upper and lower bounds of the parameters.

Results of application of the different formulae are displayed in Table 3. Rather consistent predictions were obtained for breach width, since the maximum difference between predicted values does not exceed approximately $20 \%$. All values are in the range 125-160 m.

In contrast, more variability is found in predicted breach formation time, since predictions range in-between 0.4 and $2.4 \mathrm{~h}$. Both Froehlich formulae lead to formation times exceeding $2 \mathrm{~h}$, whereas Von Thun and Gillette predict values between 0.8 and $1.1 \mathrm{~h}$ as upper bounds and between 0.4 and $0.7 \mathrm{~h}$ as lower bounds. Froehlich formulae consistently predict the largest breach widths and the longer formation times. 
Table 3 Application of empirical formulae to predict breach parameters at dam no. 2

\begin{tabular}{lllll}
\hline Reference & & $\begin{array}{l}\text { Breach } \\
\text { width (m) }\end{array}$ & $\begin{array}{l}\text { Formation } \\
\text { time (h) }\end{array}$ \\
\hline Froehlich (1987) & & & 139 & 2.1 \\
Froehlich (1995) & & 159 & 2.4 \\
Von Thun and & Standard & Erosion resistant & 126 & 0.8 \\
Gillette (1990) & & Easily erodible & 126 & 0.4 \\
& Using lateral & Erosion resistant & 126 & 1.1 \\
& erosion rate & Easily erodible & 126 & 0.7 \\
\hline
\end{tabular}

\subsubsection{Sensitivity analysis}

For the purpose of conducting fast sensitivity analysis of breach outflow with respect to breach parameters, the lumped flow model was calibrated using results of the 2D flow model. This calibration step is indeed necessary since the criteria for applicability of the lumped model "as it" are not met, as confirmed in Table 2 for the breaching in cascade of dam no. 2.

With the aim of focusing on breach outflow at dam no. 2, the breaching of this dam was considered without inflow from upstream. $Q_{1 \text {,out }}$ is thus set to zero in Eq. 10, while Eq. 12 becomes:

$$
Q_{2, \text { out }}=b \mu \sqrt{2 g\left[\max \left(Z_{2}-Z_{\mathrm{B}}, 0\right)\right]^{3}}
$$

with $b$ the breach width, $\mu$ the discharge coefficient and $Z_{\mathrm{B}}$ the elevation of breach bottom.

A first run of the lumped model, based on both fixed breach width and discharge coefficient, leads to a predicted peak outflow in excess of $81 \%$ compared to the reference. Such a discrepancy was expected in the present case, for which theoretical criteria for validity of the lumped model are not fulfilled. If the breach width $b$ is varied with $Z_{2}$, in accordance with the actual mean breach width of the wetted cross-section at each time step, the overestimation of breach outflow reduces to $54 \%$. Similarly, if the discharge coefficient is varied linearly with $Z_{\mathrm{B}}$, between the standard value $\mu=0.385$ at the initial stage and a calibrated value for the final breach bottom elevation, the error on the predicted outflow becomes $14 \%$. Finally, if both $b$ and $\mu$ are varied, then a satisfactory agreement is obtained between the prediction of both models (difference lower than 5\%) in terms of peak outflow and time of peak discharge.

The lumped model was next applied to compute approximate breach hydrographs for the case of scenario 2. The inflow $Q_{1 \text {,out }}$ in Eq. 10 was given by a $2 \mathrm{D}$ simulation of drawdown of reservoir no. 1, while the outflow $Q_{2 \text {,out }}$ was evaluated at each time by means of Eq. 13.

Figure 7 confirms a relatively low sensitivity of the breach outflow with respect to the selected breach parameters. Breach parameters from both Froehlich formulae consistently lead to a peak discharge of the order $1.28-1.30 \times 10^{4} \mathrm{~m}^{3} / \mathrm{s}$, whereas simulations based on breach parameters deduced from Von Thun and Gillette formulae predict peak discharges in the range $1.38-1.42 \times 10^{4} \mathrm{~m}^{3} / \mathrm{s}$. In spite of a larger breach width, Froehlich predictions do not lead to the higher peak discharge as a result of significantly longer formation time. Runs based on Von Thun and Gillette predictions confirm the relatively low sensitivity of the peak outflow $Q^{*}$ with respect to the breach formation time $T_{\mathrm{f}}$, since the first-order 
sensitivity index, defined as $\left(\partial Q^{*} / \partial T_{\mathrm{f}}\right) \times\left(T_{\mathrm{f}} / Q^{*}\right)$, is found to remain of the order of $5 \%$ in magnitude. This results from the large amount of water stored in the reservoirs, which maintains a relatively stable head above the breach bottom (Dewals 2006; Dewals et al. 2007).

Figure 7 also reveals the non-monotonous evolution of peak discharge as a function of formation time. Neither the shortest $(0.4 \mathrm{~h})$ nor the longest formation time $(1.1 \mathrm{~h})$ leads to the highest peak outflow, which is obtained for formation times of about $0.75 \mathrm{~h}$.

Consequently, from the standpoint of emergency planning, realistic and conservative breach parameters correspond to a breach of the order of $125 \mathrm{~m}$ in width, with a formation time of approximately $0.75 \mathrm{~h}$. From the standpoint of risk analysis, the alternative prediction of a breach width in the range 140-160 m with a formation time slightly above $2 \mathrm{~h}$ should also be investigated.

\subsubsection{Global simulation and inundation modeling in the valley}

Finally, a global unsteady 2D flow simulation was carried out, coupling the flows in the reservoirs and in the whole downstream valley. The simulation mesh was based on a grid of about 900,000 computation cells $(8 \mathrm{~m} \times 8 \mathrm{~m})$.

Transient topography was accounted for to reproduce dam failures in cascade.

Among the wide range of criteria implemented in the model for failure initiation (Sect. 4.2), the criterion of the "National Weather Service" (NWS) was used here. It corresponds to an overflow of $30 \mathrm{~cm}-1.5 \mathrm{~m}$ above the dam crest (Marche 2004). Sensitivity analysis was conducted to show that, if the threshold overtopping depth is varied between $30 \mathrm{~cm}$ and $1.5 \mathrm{~m}$, the rising limb of the breach hydrograph is slightly shifted in time but the induced changes in the peak outflow remain lower than $1 \%$.

In accordance with the previously determined breach parameters and consistently with failure mode no. 2 sketched in Fig. 3, a realistic breaching mechanism for rockfill embankments was reproduced in the $2 \mathrm{D}$ flow model by a time-dependent variation in the topography triggered by the failure criterion.

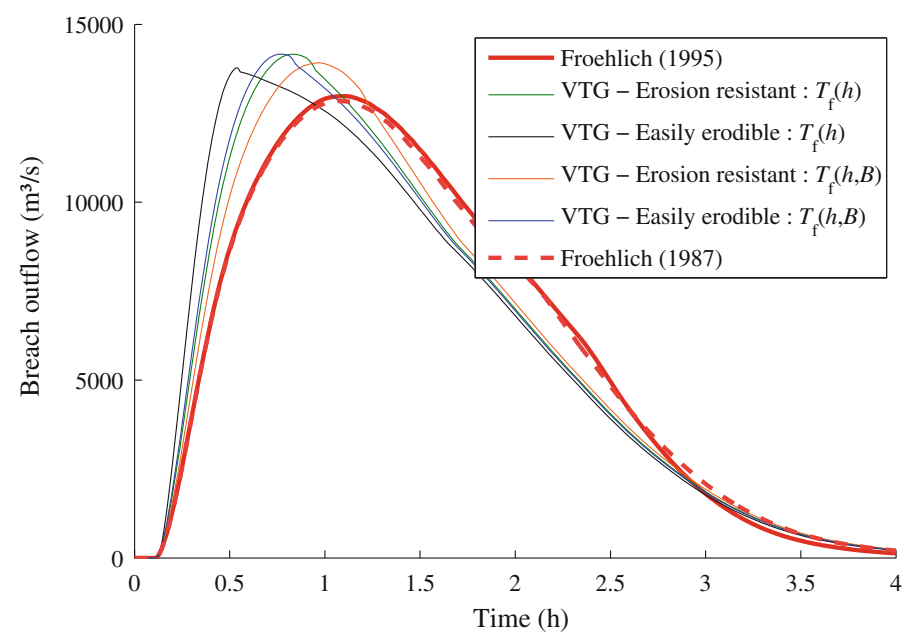

Fig. 7 Breach outflow computed by the calibrated lumped model for six different sets of breach parameters. "VTG" stands for Von Thun and Gillette (1990) 


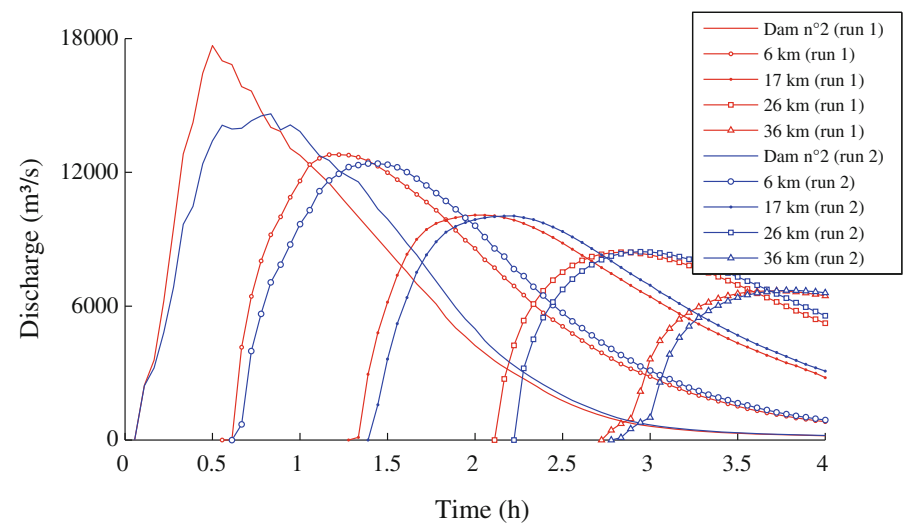

Fig. 8 Hydrographs corresponding to Run 1 and Run 2 in the 36 first kilometers of the downstream valley

Two simulations were run based on breach parameters corresponding basically to the predictions of Von Thun and Gillette and Froehlich formulae: $B=125 \mathrm{~m}$ and $T_{\mathrm{f}}=0.75 \mathrm{~h}$ (run 1 ); $B=150 \mathrm{~m}$ and $T_{\mathrm{f}}=2 \mathrm{~h}$ (run 2).

In a general way, results show that the breach parameters directly influence the flood wave only in the upper part of the downstream valley. Further downstream, the time of arrival of the wave is shifted depending on the formation time, but the extent of the flood and the maximum levels are mainly insensitive to the breach parameters, as previously stated by other authors (Wahl 1998; Marche 2004).

In particular, the sensitivity of the peak discharges with respect to the breach formation time, and the breach geometry is quickly attenuated toward downstream, as confirmed in Fig. 8 which shows that the difference in peak discharge is about $20 \%$ immediately downstream of the complex of dams, $4 \% 6 \mathrm{~km}$ downstream and already below $1 \%$ less than $17 \mathrm{~km}$ downstream of the complex. Comparison of simulation results also confirms remaining significant lags, as high as $900 \mathrm{~s}$ between run 1 and run 2, concerning both the time of arrival of the front and of peak discharge.

\section{Conclusion}

A methodology has been developed to address the main issues related to the analysis of flows induced by failures and malfunctions on a complex or a series of dams. The methodology accounts for different types of incidents, including failure or breaching in cascade, and involves sensitivity analysis.

The approach relies on two complementary numerical models, namely a two-dimensional one and a lumped model requiring very low computation time. The $2 \mathrm{D}$ model was previously shown to succeed in performing reliable and accurate simulations of dam break flows. Guidelines of practical interest were identified to select the most suitable model for each specific application, based on two non-dimensional numbers serving as criteria for assessing the validity of the lumped model. In cases where these criteria are not fulfilled for the simplified model to be applied "as it", it may still prove helpful for efficiently conducting sensitivity analysis after a proper calibration based on results of the 2D model. Such a procedure outlines the benefits of combining a sophisticated 2D flow model with a simplified one. 
The methodology was successfully applied to the simulation of flows induced by several failure scenarios on a real complex of dams, involving collapse and breaching of dams in cascade. Comparisons between the results of the $2 \mathrm{D}$ model and those of the lumped model confirmed the possibility of predicting the applicability of the lumped model from the two non-dimensional numbers mentioned before.

To face the scarcity and complexity of data on embankment material for real-life applications, breaching of embankment dams was here reproduced using a parametric time-varying topography coupled with the flow model. Realistic breaching mechanisms for rockfill dams are incorporated in the $2 \mathrm{D}$ model, and breach initiation is triggered based on a threshold value of overtopping depth, velocity, discharge or unit discharge. Breach parameters were deduced from standard empirical prediction formulae, and extensive sensitivity analysis of the outflow was conducted by means of the calibrated lumped model.

As an output, the simulations provide the figures of primary interest for emergency planning and risk analysis, including the sequence of successive overtopping and failures of dams, the time evolution of the flow characteristics (water surface elevation and velocity) at all points of the reservoirs, hazard maps in the downstream valley as well as hydrographs and limnigraphs at strategic locations in the valley.

Further developments are currently in progress, focusing on simulations taking into account morphological changes as well as collapse of buildings or mobile weirs in the downstream valley.

Acknowledgments The authors gratefully acknowledge the division "Direction générale opérationnelle de la Mobilité et des Voies hydrauliques" of the "Service Public de Wallonie" (SPW) for funding part of the research project and for providing data such as the Digital Surface Model.

\section{References}

Alcrudo F, Garcia-Navarro P (1993) A high resolution Godunov-type scheme in finite volumes for the 2D shallow-water equations. Int J Numer Methods Fluids 16:489-505

Alcrudo F, Garcia-Navarro P, Saviron J-M (1992) Flux difference splitting for 1D open channel ow equations. Int J Numer Methods Fluids 14(9):1009-1018

Anastasiou K, Chan CT (1997) Solution of the 2D shallow water equations using finite volume method on unstructured triangular meshes. Int J Numer Methods Fluids 24:1225-1245

Bellos CV, Sakkas JG (1987) 1-D Dam-break flood-wave propagation on dry bed. J Hydraul Eng-ASCE 113(12):1510-1524

Brufau P, Garcia-Navarro P (2000) Two-dimensional dam break flow simulation. Int J Numer Methods Fluids 33:35-37

Caleffi V, Valiani A, Zanni A (2003) Finite volume method for simulating extreme flood events in natural channels. J Hydraul Eng-ASCE 41(2):167-177

Dewals B (2006) Une approche unifiée pour la modélisation d'écoulements à surface libre, de leur effet érosif sur une structure et de leur interaction avec divers constituants. PhD thesis, University of Liege

Dewals BJ, Erpicum S, Archambeau P, Detrembleur S, Pirotton M (2006a) Depth-integrated flow modelling taking into account bottom curvature. J Hydraul Res 44(6):787-795

Dewals BJ, Erpicum S, Archambeau P, Detrembleur S, Pirotton M (2006b) Numerical tools for dam break risk assessment: validation and application to a large complex of dams. In: Hewlett $\mathrm{H}$ (ed) Improvements in reservoir construction, operation and maintenance. Thomas Telford, London, pp 272-282

Dewals BJ, Archambeau P, Erpicum S, Detrembleur S, Pirotton M (2007) Sensitivity analysis of the peak outflow induced by the breaching of embankment dams. In: Rutschmann P (ed) Proceedings of 14th German Dam symposium \& 7th ICOLD European club dam symposium. Technische Universität München, München, pp 86-92

Dewals BJ, Detrembleur S, Archambeau P, Erpicum S, Pirotton M (2008a) Detailed 2D hydrodynamic simulations as an onset for evaluating socio-economic impacts of floods considering climate change. 
In: Samuels P, Huntington S, Allsop W, Harrop J (eds) Flood risk management: research and practice. Taylor \& Francis, London, pp 125-135

Dewals BJ, Kantoush SA, Erpicum S, Pirotton M, Schleiss AJ (2008b) Experimental and numerical analysis of flow instabilities in rectangular shallow basins. Environ Fluid Mech 8:31-54

Dupont E, Dewals BJ, Archambeau P, Erpicum S, Pirotton M (2007) Experimental and numerical study of the breaching of an embankment dam. In: Proceedings of 32nd IAHR Biennial Congress-Harmonizing the demands from art and nature, Venice, $10 \mathrm{pp}$

Erpicum S (2006) Optimisation objective de paramètres en écoulements turbulents à surface libre sur maillage multibloc. PhD thesis, University of Liege

Erpicum S, Meile T, Dewals BJ, Pirotton M, Schleiss AJ (2009) 2D numerical flow modeling in a macrorough channel. Int J Numer Methods Fluids 61(11):1227-1246

Erpicum S, Dewals BJ, Archambeau P, Pirotton M (2010a) Dam-break flow computation based on an efficient flux-vector splitting. J Comput Appl Math 34(7)

Erpicum S, Dewals BJ, Archambeau P, Detrembleur S, Pirotton M (2010b) Detailed inundation modelling using high resolution DEMs. Eng Appl Comput Fluid Mech 2(4):196-208

Fennema RJ, Chaudhry H (1990) Explicit methods for 2-D transient free surface flows. J Hydraul EngASCE 116(8):1013-1034

Fread DL (1984) DAMBRK: the NWS Dam Break flood forecasting model. National Weather Service (NWS) Report, Silver Spring

Froehlich DC (1987) Embankment-Dam Breach parameters. In: Proceedings of 1987 ASCE national conference on hydraulic engineering, Williamsburg, pp 570-575

Froehlich DC (1995) Embankment dam breach parameters revisited. In: Proceedings of the 1995 ASCE conference on water resources engineering, San Antonio, pp 887-891

Garcia-Navarro P, Fras A, Villanueva I (1999) Dam-break flow simulation: some results for one-dimensional models of real cases. J Hydrol 216:227-247

Glaister P (1988) Approximate Riemann solutions of the shallow water equations. J Hydraul Res 26(3):293-300

Hervouet J-M (2003) Hydrodynamique des écoulements à surface libre - Modélisation numérique avec la méthode des éléments finis. Presses de l'école nationale des Ponts et Chaussées, Paris

ICOLD (1998) Dam Break flood analysis-review and recommendations, Bulletin 111. International Commission on Large Dams, Paris

Kamrath P, Disse M, Hammer M, Köngeter J (2006) Assessment of discharge through a dike breach and simulation of flood wave propagation. Nat Hazards 38(1-2):63-78

Kerger F, Archambeau P, Erpicum S, Dewals BJ, Pirotton M (2009) A fast universal solver for 1D continuous and discontinuous steady flows in rivers and pipes. Int $\mathbf{J}$ Numer Methods Fluids. doi: 10.1002/fld.2243

Kerger F, Erpicum S, Dewals BJ, Archambeau P, Pirotton M (2010) 1D unified mathematical model for environmental flow applicated to aerated mixed flows. Adv Eng Softw (in press)

Khuat Duy B, Archambeau P, Dewals BJ, Erpicum S, Pirotton M (2010) River modelling and flood mitigation in a Belgian catchment. Proc ICE Water Manag 163(8):417-423

Louaked M, Hanich L (1998) TVD scheme for the shallow water equations. J Hydraul Res 36(3):363-378

MacDonald TC, Langridge-Monopolis J (1984) Breaching characteristics of dam failures. J Hydraul EngASCE 110(5):567-586

Marche C (2004) Barrages: crues de rupture et protection civile. Presses Internationales Polytechniques

Marche C, Gagnon J, Quach T-T, Kahawita R, Beauchemin P (1997) Simulation of dam failures in multidike reservoirs arranged in cascade. J Hydraul Eng-ASCE 123(11):950-961

Mingham CG, Causon DM (1998) High-resolution finite volume method for shallow water flows. J Hydraul Eng-ASCE 124(6):605-614

RESCDAM (2000) The use of physical models in dam-break flood analysis-final report. Helsinki University of Technology

Roger S, Dewals BJ, Erpicum S, Schwanenberg D, Schüttrumpf H, Köngeter J, Pirotton M (2009) Experimental und numerical investigations of dike-break induced flows. J Hydraul Res 47(3): 349-359

Schwanenberg D, Harms M (2004) Discontinuous Galerkin finite-element method for transcritical twodimensional shallow water flows. J Hydraul Eng-ASCE 130(5):412-421

Singh KP, Snorrason A (1984) Sensitivity of outflow peaks and flood stage to the selection of dam breach parameters and simulation models. J Hydrol 68:295-310

Tseng MH, Chu CR (2000) Two dimensional shallow water flows simulation using TVD-MacCormack scheme. J Hydraul Res 38(2):123-131 
Von Thun JL, Gillette DR (1990) Guidance on breach parameters. Unpublished internal document, US Bureau of Reclamation, Denver, $17 \mathrm{pp}$

Wahl TL (1998) Prediction of embankment dam breach parameters, a literature review and needs assessment. DSO-98-004, Dam Safety Office, Water Resources Research Laboratory, US Bureau of Reclamation, Denver

Wahl TL (2004) Uncertainty of prediction of embankment dam breach parameters. J Hydraul Eng-ASCE 130(5):389-397 